\title{
SUPLEMENTO AL INVENTARIO DE LA FÁBULA GRECO-LATINA. ÉPOCAS ARCAICA, CLÁSICA Y HELENÍSTICA. ${ }^{1}$
}

\author{
dedicado a Francisco Rodríguez Adrados
}

In this article the author presents those fables occurring in Archaic, Classical, and Hellenistic Greek literature which can be added to F. R. Adrados' Inventario y documentación de la fábula greco-latina. These fables can be found in a great variety of other literary genres, viz. in the works of epic and lyric poets, tragedians and comedians, satyric playwrights and epigrammatists, rhetoricians, orators, historiographers, and philosophers. All of the passages that will be discussed are of intrinsic importance as they predate the versions extant in the fable collections. Moreover, many of the supplementary references given below are more or less significant variations on well-known fable themes, whereas others are actually unique in the ancient fable corpus.

Como se sabe, la Historia de la fábula greco-latina de Francisco Rodríguez Adrados ${ }^{2}$ es una obra de referencia muy importante en el amplio campo de la fábula antigua. El tercer volumen de este magnum opus es un amplio e

1 Este artículo lo escribí en Madrid en los meses de Julio y Agosto de 1997, durante mi estancia en el Instituto de Filología, gracias a una beca del Consejo Superior de Investigaciones Científicas. Quisiera agradecerle a todo el equipo del DGE su amable hospitalidad. La corrección de mi castellano por Juan Rodríguez Somolinos y la asistencia con la informática por José Antonio Berenguer y Daniel Riaño se la agradezco mucho.

2 Empleo las siguientes abreviaturas: Adrados F.R. Adrados, Historia de la fábula greco-latina, vol. III: Inventario y documentación de la fábula greco-latina, Madrid, Editorial de la Universidad Complutense, 1987; Aes. = B.E. Perry, Aesopica, vol. I: Greek and Latin Texts, Urbana, Illinois, University Press, 1952 (reimpr. New York, Arno Press 1980); H.= A. Hausrath - H. Haas - H. Hunger (edd.), Corpus Fabularum Aesopicarum, vol. I: Fabulae Aesopicae soluta oratione conscriptae, 1-2, Leipzig, Teubner, 1959-19702; VD =

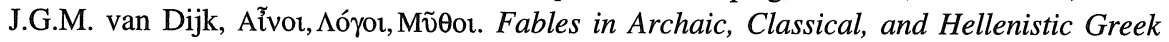
Literature. With a Study of the Theory and Terminology of the Genre, Leiden/New York/Köln, Brill, 1997 (tesis de la Universidad Católica de Nimega). 
impresionante inventario de la fábula greco-latina ${ }^{3}$. No obstante puede aumentarse con numerosas referencias que se encuentran diseminadas por toda la literatura griega y latina, especialmente fuera de las colecciones (las llamadas fábulas-ejemplo). A veces se trata de meras referencias suplementarias, que no difieren esencialmente de las demás versiones existentes. Otras veces son variantes más o menos importantes de las versiones conocidas de estas fábulas. Por último, hay algunas fábulas nuevas, más o menos independientes del resto de la tradición fabulística antigua. En este artículo presento las referencias fabulísticas suplementarias de la literatura griega arcaica, clásica, y helenística. Es obvio que en muchos casos estas son las versiones más antiguas conservadas, ya que las colecciones de fábulas greco-latinas que han llegado hasta nosotros datan de la época imperial.

\section{Nuevas fábulas.}

A\A. 717-736 (12F1 VD), Ar.VRa. 1431-1432 ([A.] AP 10..11O; fr. 452 Radt **) (17A6 VD; no está en Aes.). Pienso que el famoso «tema del león» ${ }^{4}$ del Agamenón, una narración que contiene un tema (la naturaleza) y unas características ${ }^{5}$ típicamente fabulísticas, debe recogerse como fábula separada ${ }^{6}$ : fábula de un cachorro de león criado por un hombre en su casa. En las Ranas, el Esquilo de Aristófanes alude a esta misma fábula ${ }^{7}$, aplicándola a Alcibíades en lugar de a Helena.

Phaedo, Zopyr. fr. 1 Rossetti (51F1ab VD; no está en Aes.). Fábula de un príncipe y un cachorro de león que se educaron juntos y eran amigos íntimos. No es seguro que esta fábula esté relacionada con la del Agamenón (véase supra), ya que no se ha conservado, excepto dos fragmentos brevísimos que nos transmite Teón (Prog. 3, II 74-75 Spengel [p. 34 Patillon-Bolognesi]).

S., Aj. 1150-1156 (13F2 VD; Aes. T72 ${ }^{8}$ ) Sugiero que este ejemplo (de un hombre y los demás), con el que Teucro contesta muy irónica y críticamente

3 Actualmente, se prepara una edición revisada y aumentada de los tres volúmenes.

4 Véase F. R. Adrados, «El tema del león en el Agamenón de Esquilo (717-49)», Emerita 33, 1965, pp. 1-5; J.A. Schuursma, «Aeschyli Apologus», Mnemosyne n.s. 60, 1933, pp. 179-192. No es una «parábola», como dicen B. M. W. Knox, «The Lion in the House (Agamemnon 717-36 [Murray]», CPh 47, 1952, pp. 17-25, y Chr. Nappa, «Agamemnon 717-36: The Parable of the Lion Cub», Mnemosyne 47, 1994, pp. 82-87.

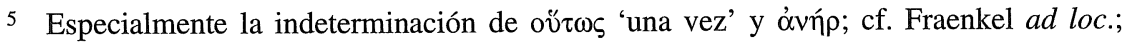
Adrados I, p. 385.

6 Aunque pueden compararse H. 225 y H. 276, que tratan de lobos, no de leones; véase Adrados, p. 221, p. 259.

7 Puede compararse también H. 419; véase Adrados, pp. 159-160.

8 Curiosamente, Perry incluía esta fábula bajo los «testimonios»; véase mi «Addenda 
al ejemplo anterior de Menelao ${ }^{9}$, luchando contra él con sus propias armas ${ }^{10}$, debe ser incluido como fábula independiente. El pasaje contiene varias características típicas de este género ${ }^{11}$. Trímetros yámbicos.

Timocr., fr. 4 PMG (10F1 VD; no está en Aes.). Fábula de las palomas que escaparon a un sacrificio a Adonis, amante de Afrodita, pero cayeron en otra hoguera. La fábula, que ilustra el tema del destino, se aduce en dos tratados paremiográficos (una vez parafraseada, otra en una cita desgraciadamente muy fragmentaria) como ejemplo de una fábula cipria ${ }^{12}$.

\section{Referencias suplementarias de fábulas conocidas}

H. 3 (Adrados p. 35): Ar., Lys. 695 (17A5 VD; Aes. 3). Alusión a la fábula del águila y el escarabajo, que se convirtió en un proverbio y se incluyó en dos formas distintas - en las colecciones paremiográficas ${ }^{13}$.

H. 63 (Adrados, p. 84): Demad. fr. 22 De Falco (41F1 VD; Aes. 63). Mera referencia a la fábula de Deméter, la golondrina y la anguila, atribuida a Démades, quien - según la anécdota - se la contó a los atenienses en cierta ocasión en que no le prestaban atención. Aunque la autenticidad de la adscripción no puede establecerse con seguridad, Démades parece haber tenido alguna experiencia con auditorios poco atentos ${ }^{14}$; además parece ser que el orador mostraba predilección por expresiones metafóricas ${ }^{15}$ (como es una fábula). La fábula está también atribuida a Démades (Demas) en la colección humanista de Leonardo Dati (número 40) ${ }^{16}$, que, curiosamente, sustituye a Deméter por una alondra.

ad Aesopica. Unnoticed and Neglected Themes and Variations of Greek and Latin Fables», Bestia 6, 1994, p. 96, p. 110.

9 Ibid. $1142-1149$ = no H. 145 (Adrados, p. 349).

10 Cf. C. M. Bowra, Sophoclean Tragedy, Oxford, Clarendon Press, 1944, p. 54.

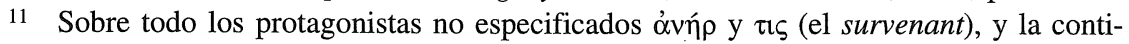
nuativa $\kappa \tilde{\alpha} \tau$ '.

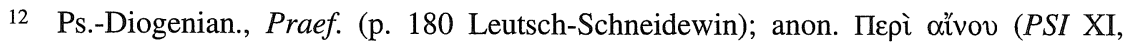
1935, p. 154).

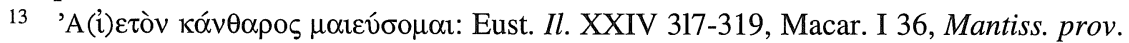
I 2; $\mu \alpha 1 \varepsilon v ́ \varepsilon \tau \alpha t:$ Zen. I 20, Diogenian. I 65V, II 44, Greg. Cypr. I 55M, I 57, Apostol. I 50 (= Arsen. I 69), Erasm., Adag. III 7.1, rechazando, con razón, la uaria lectio $\mu \alpha i ́ \varepsilon \tau \alpha 1$.

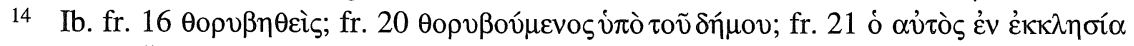

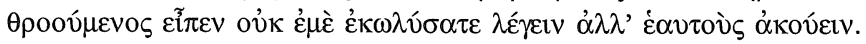

15 Cf. ib. fr. 12-13, 15, 17-18, 20, 23-26, 84 De Falco.

16 O. Tacke, «Eine bisher unbekannte Äsopübersetzung aus dem 15. Jahrhundert», RhM 67, 1912, pp. 298-299. 
H. 83 (Adrados, pp. 100-101): Ar., Ach.120 (17A1 VD; Aes. 81). Alusión a la fábula de la zorra y el mono, o más exactamente a la versión de Arquíloco ${ }^{17}$ de dicha fábula. En Aristófanes, Diceópolis cita - mejor dicho parodia - un fragmento de la fábula (perdida) de Arquíloco, cambiando unas vocales, $\mathrm{y}$, en consecuencia, el sentido completo: «y teniendo esa barba [ $\pi \omega \gamma^{\prime} \omega v^{\prime}$, en vez de 'ese culo' ( $\pi v \gamma \eta ́ v)] . . . »$. El juego de palabras, típicamente aristofánico, es explicado por el escoliasta, que nos transmite el fragmento de la fábula original.

H. 136 (Adrados, pp. 142-145): Democr. fr. 224 Diels-Kranz (47A1 VD; Aes. 133). Alusión a la fábula del perro que llevaba carne, más exactamente a la línea $1^{18}$ de dicha fábula. La alusión viene indicada por la adscripción a Esopo («el perro esópico»). El fragmento está conservado en Estobeo (3.10.68).

H. 158 (Adrados, pp. 168-169): D. fr. 13 Baiter-Sauppe ap. Aristobul. FGrHist 139F3 ap. Plu., Dem. 23.5 (40F1 VD; Aes. 153). Es la fábula de las ovejas que entregaron los perros a los lobos. Según el testimonio de Plutarco, el historiador Aristóbulo dijo que esta fábula se la contó Demóstenes a los atenienses cuando Alejandro exigió que los oradores más prominentes de la ciudad se entregaran a él, para advertirles, por supuesto, de que no lo hicieran (los lobos destrozaron el rebaño). La fábula es también atribuida a Demóstenes por dos autores latinos tardíos - que pueden añadirse a M. 330 (Adrados, p. 515): Isid., Etym. I 40 y Melanchthon, De utilitate fabularum ${ }^{19}$. Plutarco solamente alude a la fábula, mientras que los testimonios latinos presentan versiones completas. Estas dos versiones latinas conservan una variante con respecto a las demás versiones: complican el relato añadiendo unos pastores con los que los lobos hablan sobre la entrega de los perros. Además, San Isidoro modifica el contexto, sustituyendo a Alejandro por su padre, Filipo, y aumentando el número ${ }^{20}$ de oradores exigidos por el macedonio. En cuanto a la problemática adscripción de esta fábula a Demóstenes, lo más que puede decirse es que, por un lado, sabemos que Demóstenes pronunció un discurso ante sus conciudadanos en esta situación ${ }^{21}$, y que, por otro lado, la imagen de los perros protegiendo las ovejas contra los lobos está ampliamente difundida

17 Archil. fr. 185-187 West; Epod. VI Adrados.

18 Véase Adrados, p. 143.

19 C. G. Bretschneider, Corpus Reformatorum, vol. XI: Philippus Melanchthon. Opera quae supersunt omnia, Halle-Saale, Schwetschke, 1843, col. 119.

20 Ocho en Plutarco; diez en San Isidoro. Por lo demás, hay nueve en Arr., An. I 10.4.

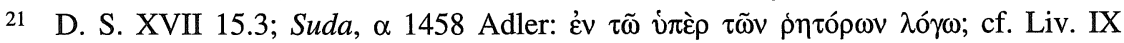
18.7. 
en la literatura griega clásica ${ }^{22}$. Es más, en algunos pasajes (dos de los cuales se adscriben también a Demóstenes) se habla de perros que dejan de cumplir su función de guardianes (como en la fábula) ${ }^{23}$. Por último, un collega proximus de Demóstenes habría utilizado la misma imagen (pero no la fábula) en el mismo contexto histórico (contra Alejandro) ${ }^{24}$.

H. 253 (Adrados, pp. 241-242): Antipho Soph., fr. 54 Diels-Kranz (45F1 VD; Aes. 225). Es una variante muy diferente de la fábula del avaro que está incluida en las colecciones anónimas. Se trata de una versión mucho más elaborada y sutil. En primer lugar, se complica el relato añadiendo una relación entre el avaro que enterró su dinero y el hombre que le consoló cuando se lo había llevado: el segundo le preguntó al primero si accedería a prestarle su dinero a interés, pero él no se fiaba de los demás y por eso prefirió enterrarlo. Ambos hombres se encontraron de nuevo después de que el tesoro había sido robado por un tercero. Además, en conexión con ello, la moraleja de la fábula difiere de la de las versiones anónimas: se critica al hombre que enterró su tesoro no solo porque no lo utilizó sino también porque dejó de aumentarlo (con los intereses). Finalmente, la fábula contiene cuatro palabras polísemas ${ }^{25}$, y el epimitio una metáfora ${ }^{26}$. Ambos elementos acentúan su significación monetaria pero han sido omitidos en la versión reducida incluida en las colecciones. La fábula la transmite Estobeo (III 16.30).

(¿H. 254?) Achae., TragGrF I 20F34 (15A1 VD), Menedemus Eretr. ap. D.L. 2.17 (53A1 VD) (¿Aes. 226?). Alusión a una fábula de una tortuga y un águila. Es claro que la primera triunfa sobre la segunda, pero no cómo, puesto que sólo se conservan dos trímetros yámbicos citados por Diógenes Laercio y, mucho más tarde, por Erasmo de Roterdam (Adag. I 7.68). En todo caso, no puede tratarse de la única fábula que conocemos con estos dos protagonistas, ya que en ésta es la tortuga la que lleva las de perder ${ }^{27}$. Sí podría tratarse de una variante de la famosa carrera de la tortuga y la liebre, paradójicamente ganada por el «underdog». Según Diógenes y el gran humanista neerlandés, la fábula es aplicada por Aqueo en su drama satírico Omfale, posiblemente a Heracles, y por Menedemo a sus adversarios políticos.

22 Cf. Ar.,Eq. 1017, 1022-1023, Vesp. 894ss.; Thphr., Char. 29.5; X., Mem. II 7.13-14 (Adrados, p. 384; 50F1 VD). Véase p.e. C. Mainoldi, L'image du loup et du chien dans la Grèce ancienne d'Homère à Platon, Paris, Ophrys, 1984, pp. 156-160.

23 [D.] 25.40, [D.] 26.22; Pl., Lg. 906d, R. III 416a.

24 Demad. fr. 84 De Falco.

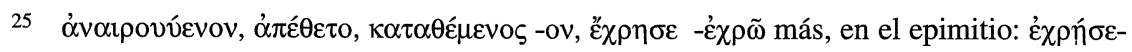
$\tau \propto \imath-\chi \rho \hat{\sigma} \sigma \varepsilon \tau \alpha$.

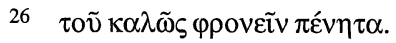

27 H. 259 (Aes. 230, 490); Adrados, pp. 246-247, 429 (M. 25). 
H. 255 (Adrados, pp. 243-244): Antip. Sid., AP 7.210 (27F1 VD; cf. Aes. 227). Nueva variante de la fábula de la golondrina y la serpiente, recogida en varias colecciones. Por un lado, no se especifica el lugar en el que la golondrina hizo su nido (un tribunal en las colecciones); por otro lado, se añade que finalmente sí hubo justicia: la serpiente regresó para devorar también a la propia golondrina, pero cayó en el hogar y murió. El epigrama es citado por el Suda varias veces (pero sólo parcialmente) y resumido por el lematista ${ }^{28}$.

H. 273 (Adrados, pp. 256-257): Ar., Av. 807-808 (17A4 VD; Aes. 276). Es una cita del final de la fábula esquílea del águila herida por una flecha $(12 \mathrm{~F} 1$ VD). Se citan, más exactamente, las palabras del águila lamentando morir por culpa de sus propias plumas ${ }^{29}$. La cita es literal, pero la intención aristofánica es paratrágica.

no H. 4 (Adrados, pp. 282-283): Demetr., Eloc. 157 (43A1 VD). Demetrio cita de la fábula aristotélica del hombre que cometió un agravio contra su huésped (57A1 VD), como ejemplo de una fábula divulgada.

no H. 178 (Adrados, p. 363): Antisth., fr. 100 Caizzi (48F1 VD). Es la fábula (perdida) de los leones y las liebres a la que alude Aristóteles (52A 1 VD). Ambos filósofos la aplican a la política, pero diferentemente.

no H. 231 (Adrados, p. 386): Ibyc. 32, fr. 313 PMG (8F1 VD) ap. Chrysipp. Stoic., fr. 180.14 SVF (56A1 VD); Aristias, TragGrF (Snell) 9F8 (11F1 VD); Apolloph., fr. 9 CAF (18F1 VD); Nic., Ther. 343-358 (3F1 VD) (Aes. 458). Pueden añadirse varias referencias a esta fábula (fábula etiológica del asno y la serpiente). Primeramente, Eliano (NA 6.51) dice que esta fábula fue utilizada no solo por Dinóloco y Sófocles sino también por Aristias y Apolófanes; sin embargo, las versiones de estos dos poetas dramáticos no se han conservado. En segundo lugar, es probable ${ }^{30}$ que un fragmento de Íbico transmitido por Crisipo pertenezca a la versión de esta fábula a la que se refiere también Eliano. Finalmente, esta fábula la relata in extenso Nicandro. Se trata de una versión muy elaborada, en hexámetros dactilicos. Cuando se compara con la versión transmitida por Eliano, la del poeta helenístico se distingue por el uso frecuente de los llamados «kenningar» ${ }^{31}$, perífrasis enigmáticas: los protagonistas no son mencionados directamente, sino tan solo aludidos de modo más

28 Suda $\propto$ 687, ع 3246, $\eta$ 251, 525, к 1654, $\tau 390$ Adler; lemm. ad loc. (27T1a-f, 27T4 VD).

29 A., fr. 139.4-5 Radt; véase mi «Intertextualiteit in de Griekse literatuur. De functie van een fabel van Aeschylus tot Eustathius», Kleio 22, 1993, pp. 141-157.

30 Véase M. Davies, «The ancient Greeks on why mankind does not live forever», $M H$ 44, 1987, pp. 72-73.

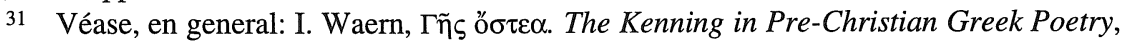
Diss. Uppsala, Almqvist \& Wiksell, 1951. 
o menos explícito ${ }^{32}$. El poeta mismo ha escondido su nombre en un acróstico

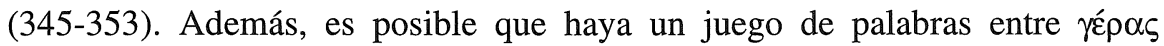
'regalo' y $\tilde{\eta} \rho \alpha \varsigma$ 'senectud': ¡los hombres perdieron lo primero para «ganar» lo segundo!

no H. 250 (Adrados, p. 394): Theopomp. Hist., FGrHist 115F27 (35F1 VD; Aes. 367). Teón (Prog. 2) se refiere a «la fábula de la Guerra y la Violencia en el vigésimo libro de la Historia de Filipo de Teopompo» como ejemplo clásico que los alumnos tendrían que aprender de memoria. Desafortunadamente, la fábula del historiador no se nos ha conservado, pero es probable ${ }^{33}$ que se trate de una versión de una fábula etiológica babriana (70), que es la única que conocemos con estos dos protagonistas, y que explica por qué la violencia es siempre seguida automáticamente por la guerra.

\section{Testimonios inseguros o dudosos.}

Para ser completo, menciono a continuación algunas referencias suplementarias a fábulas griegas arcaicas, clásicas o helenísticas que son, sin embargo, más o menos dudosas.

no H. 19 (Adrados, p. 291): Arist. fr. 573 Rose (34F1A1 VD; Aes. 427). Según el escoliasta de Aristófanes (Av. 471), Aristóteles, en su Constitución de los Samios, presentó a Esopo contando una fábula, pero no se dice cuál. La identificación de esta fábula desconocida con la de la zorra y el erizo, que Aristóteles en otra obra ( $R h$. II 20) sí presenta como narrada por el fabulista legendario, es puramente hipotética.

no H. 142 (Adrados, pp. 347-348): Theoc. 7.23 (ap. Gal., Simp. med. temp. 11.37) (21A1 VD; Aes. 447). Según Galeno, algunos derivan el epíteto de la alondra crestada en Teócrito de la fábula etiológica aristofánica de la alondra enterrando a su padre en su cabeza (Av. 471-475). Sin embargo, es más probable que el adjetivo sencillamente se refiera al lugar donde normalmente se ven estos pájaros: cerca de las tumbas ${ }^{34}$.

no H. 154 (Adrados, p. 352): Th. ap. $\Sigma 4.92$ (32 VD; Aes. 331). Un escoliasta afirma que un pasaje de Tucídides deriva de la fábula babriana del perro y la liebre, pero no puede ser así.

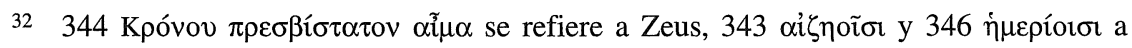

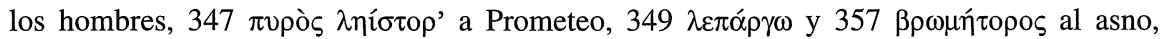

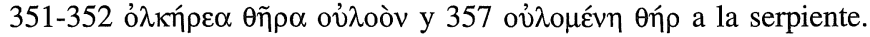

33 Pero no seguro (contra O. Crusius, «Theopomp bei Babrius», Philologus 54 (n.s. 8), 1895, p. 745).

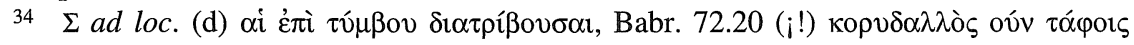
$\pi \alpha i \zeta \omega v$. 
no H. 194 (Adrados, p. 370): Pl., Phdr. 272c (p. 669 VD). Un escoliasta y un comentarista (Herm.) de Platón hacen derivar la expresión «las palabras del lobo» de la fábula del lobo y los pastores comiendo un cordero, pero no es seguro que tengan razón ambos intérpretes.

Quisiera terminar este artículo español con un curioso pasaje del obispo de Híspalis. Isidoro de Sevilla (Etym. I 40) afirma que el inventor del género de la fábula fue Alcmeón de Crotona (44 VD); dos autores tardíos lo repiten ${ }^{35}$. Sin embargo, no se encuentran fábulas entre los fragmentos del escritor crotoniata. Es posible que estas referencias tengan que relacionarse con la distinción entre los hombres y los animales que hizo Alcmeón por primera vez ${ }^{36}$, o bien con la aplicación de una metáfora médica a la política que está también en la base de la famosa fábula del vientre y los miembros del cuerpo contada por Menenio Agripa en 494 a.C. ${ }^{37}$. Sin embargo, puede ser también que el nombre del fabulista misterioso sea una corrupción del nombre del Esopo árabe, Loqman. La primera sílaba pudiera indicar el origen árabe, como en tantas otras palabras castellanas.

GERT-JAN VAN DIJK

35 Rom. Vind., Epil. (II 454 Hervieux); Conr. Hirs., Dial. super Avian. (p. 26 Huygens).

36 Thphr., Sens. 25-26 (24A5 Diels-Kranz).

37 Alcmaeon Crot. 24B4 Diels-Kranz ap. Aët. V 30.1; Liv. II 32 (véase Adrados, pp. 140-141); A. Capizzi, «Un apologo di Alcmeone crotoniate?», QUCC n.s. 13, 1983, pp. 159-163. 